\title{
FONOAUDIOLOGIA NO CONTEXTO DA EQUOTERAPIA COM CRIANÇAS AUTISTAS: UMA REINTERPRETAÇÃO A PARTIR DA NEUROLINGUÍSTICA DISCURSIVA
}

\author{
PALOMA NAVARRO ${ }^{1}$
}

\begin{abstract}
RESUMO: Partindo da teorização da Neurolinguística Discursiva (ND) - com ênfase nos estudos desenvolvidos por Vygotsky e Luria, por um lado, e os de Coudry e outros linguistas que consideram o sujeito, por outro - reinterpretamos a prática fonoaudiológica no contexto da Equoterapia. Tal reinterpretação é beneficiada pelas contribuições de Wallon, Merleau-Ponty e Desjardins, cujos estudos implicam a relação entre corpo, sistema sensorial, fala e linguagem. Para justificar tal reinterpretação, analisamos dados do acompanhamento fonoaudiológico longitudinal de sujeitos portadores de Transtorno do Espectro Autista (TEA), no contexto da Equoterapia, com o propósito de salientar os diferentes papéis que o cavalo e a fonoaudióloga desempenham na relação com a criança.

Palavras-chave: Fonoaudiologia; Equoterapia; Neurolinguística Discursiva.
\end{abstract}

\begin{abstract}
Based on the theory of Discursive Neurolinguistics (ND) - with emphasis on the studies developed by Vygotsky and Luria, on one hand, and Coudry and other linguists who consider the subject, on the other - we reinterpret the Speech-Therapy practice in the context of Equine Therapy. Such reinterpretation is benefited from the contributions of Wallon, Merleau-Ponty and Desjardins, whose studies imply the relationship between body, sensory system, speech and language. In order to justify this reinterpretation, we analyzed data from the longitudinal speech-therapy follow up of subjects with Autism Spectrum Disorder (ASD), in the context of Equine Therapy, in order to highlight the different roles that the horse and the speech therapist play in the relationship with the child.
\end{abstract}

Key words: Speech-Therapy, Equine Therapy, Discursive Neurolinguistics.

\section{INTRODUÇÃO}

A Equoterapia foi formalizada na Noruega, na década de 1950, como proposta clínica de uma equipe de profissionais, fazendo uso do cavalo como instrumento terapêutico, voltada para o acompanhamento de crianças e adultos com alterações motoras e/ou neurológicas. Na época, a equipe foi formalmente constituída por um fisioterapeuta, um psicólogo e um equitador. O $1^{\circ}$ Congresso Internacional de Equoterapia, ocorrido em 1974 na cidade de Paris, contribuiu para a difusão da prática em outros países (ANDE-BRASIL, 2014).

1 Doutora em Linguística pelo Departamento de Linguística, do Instituto de Estudos da Linguagem (IEL), da Universidade Estadual de Campinas (UNICAMP), São Paulo, Brasil. Endereço eletrônico: palomarn@yahoo.com.br 
No Brasil, a Equoterapia chegou em 1989, com esse mesmo modelo de equipe quando foi fundada a Associação Nacional de Equoterapia (ANDEBRASIL), apoiada por profissionais da saúde do Hospital do Aparelho Locomotor - Rede SARAH ${ }^{2}$. Desde então, tanto a prática quanto seu referencial teórico são regulamentados pela ANDE-BRASIL. A Equoterapia é indicada para pessoas acometidas por patologias/distúrbios, tais como: genéticos, neurológicos, psicológicos, ortopédicos, musculares, metabólicos, mentais, sequelas de traumas e cirurgias, e, ainda, dificuldades de aprendizagem e alterações de linguagem.

Ao longo do tempo, a equipe básica de profissionais recomendada pela ANDE-BRASIL foi modificada, expandindo-se com a inclusão de profissionais de outras especialidades, dentre estas o fonoaudiólogo. O trabalho fonoaudiológico com portadores de Transtorno do Espectro Autista (doravante TEA) se justifica dentro da equipe equoterápica à medida que, de acordo com o Manual Diagnóstico e Estatístico de Transtornos Mentais (DSM-V, 2013), os critérios fundamentais que diagnosticam tal patologia se concentram na área de fala e linguagem.

O levantamento bibliográfico sobre a atuação fonoaudiológica na área de Equoterapia $^{3}$, mostra que no Brasil há poucos fonoaudiólogos integrando a equipe equoterápica (VALLE et. al, 2014) e, nestes casos, há prevalência de atuação na área de Motricidade Orofacial (CANTARELLI, 2006; ALVES, 2014). O refinamento da pesquisa bibliográfica, - relacionando os termos "fonoaudiologia, linguagem e equoterapia" - identificou poucos estudos nesta área. Apenas 14 estudos, não relacionados a portadores de TEA, faziam referência à linguagem. Nestes casos, a linguagem era compreendida como um código a serviço do pensamento, vinculada à relação entre maturidade de áreas cerebrais específicas e desenvolvimento infantil. Além disso, nestes mesmos estudos, o vínculo positivo entre a criança e o cavalo se constituía como a única possibilidade para o desenvolvimento de linguagem (NASCIMENTO, MADUREIRA, 1999; SANTOS, 2000; FREIRE, 2003; FREIRE, POTSCH, 2005, 2015; JUSTI, 2009; MOTA, 2006, 2009; ANDRADE, 2010; ANDRADE, ALVES, 2014; CUNHA, 2014; VALLE et.al., 2014; PINTO, 2015). Do nosso ponto de vista, essa perspectiva se assenta em uma visão biomédica de linguagem e de sujeito, ressaltando, como mencionado, apenas o vínculo positivo da criança com o cavalo como possibilidade para o desenvolvimento de linguagem, valorizando genericamente questões perceptivas e sensoriais, consideradas no nosso estudo como imprescindíveis para o desenvolvimento da linguagem (NAVARRO, 2016).

É preciso ressaltar que a prática equoterápica no Brasil é recente - apenas nesta última década é que se estruturaram os cursos de formação em Equoterapia - e, mais recente ainda, é a participação do fonoaudiólogo como integrante da

${ }^{2}$ A Rede Sarah de Hospitais do Aparelho Locomotor surgiu em 1974 como resposta à demanda por uma estrutura especializada no tratamento de enfermidades do aparelho locomotor. Presente em diferentes regiões do país, tem seu centro de referência localizado em Brasília (DF).

${ }^{3} \mathrm{O}$ levantamento bibliográfico realizado recobre o período entre 2014 e 2016. 
equipe de profissionais da área; atuação ainda não reconhecida pelo Conselho Federal de Fonoaudiologia ${ }^{4}$.

Mesmo assim, cada vez mais se observa nas áreas da educação e da saúde (Fisioterapia, Fonoaudiologia, Terapia Ocupacional, por exemplo) o reconhecimento dos efeitos positivos da prática equoterápica (SILVA, GRUBITS, 2004; STARKE, ALBIERO, GONTAN, 2010; CUNHA, ANDRADE, ALVES 2014; ROSAN, BRACCIALLI, ARAUJO, 2016). Consideramos, no entanto, que a sua justificativa teórica é insuficiente para explicitar como a Equoterapia, de fato, afeta os praticantes, especialmente aqueles que se apresentam com dificuldades no processo de aquisição de linguagem.

Reivindicamos, assim, o suporte teórico da Neurolinguística Discursiva (ND) para justificar e explicar a prática fonoaudiológica com a linguagem no contexto da Equoterapia. Corrobora esta reivindicação o reconhecimento de que a ND se sustenta em pilares teóricos que recobrem a inter-relação entre as noções de sujeito, de cérebro e de linguagem (COUDRY, SCARPA, 1985; COUDRY, 1986/1988; COUDRY, FREIRE, 2005; COUDRY, 2010; COUDRY, BORDIN, 2012) - noções imprescindíveis para a análise da relação da criança com o cavalo, para além da "formação positiva de um vínculo".

Argumentamos que a compreensão do aspecto discursivo valorizado nas mediações (COUDRY, 1997; ABAURRE, COUDRY, 2008), neste caso as que envolvem a fonoaudióloga e a criança no contexto da Equoterapia, permite compreender os diferentes papéis atribuídos ao animal, tanto por uma quanto por outra.

Este ensaio deriva de uma pesquisa de doutorado ${ }^{5}$ que recobre o acompanhamento longitudinal fonoaudiológico no contexto de Equoterapia, ao longo de 18 meses, de quatro sujeitos com diagnósticos de TEA, com idades entre dois anos e seis meses e seis anos e sete meses. Privilegiou-se, em cada um deles, a análise e a discussão do efeito dessa prática no processo de aquisição de fala e linguagem na inter-relação com o sistema sensorial ${ }^{6}$, fundamental para tal desenvolvimento.

\footnotetext{
${ }^{4}$ Em consulta aprovada em sessão plenária ordinária, no dia 31/08/2008, foi reconhecido que o fonoaudiólogo pode atuar como membro da equipe multidisciplinar de Equoterapia. Disponível em <http://www.fonosp.org.br/legislacao/consultas-do-crfa-2\%C2\%AA-regiao/consulta-n-0308/> Acesso em: 02/01/2018.

${ }^{5}$ Tese defendida em 2016 no Instituto de Estudos da Linguagem, (UNICAMP) por Navarro: "Fonoaudiologia no Contexto da Equoterapia: um estudo neurolinguístico de crianças com Transtorno do espectro Autista", orientada pela Profa. Dra. Maria Irma Hadler Coudry e co-orientada pela Profa. Dra. Sonia Sellin Bordin. O estudo discute a prática fonoaudiológica no contexto da Equoterapia; o contraste entre as noções de corpo das áreas de Equoterapia e de Fonoaudiologia; a relação entre o sistema perceptual e a aquisição da fala e de linguagem; a importância do ritmo e a seletividade atencional da criança; dentre outros temas. O papel do ritmo no desenvolvimento do sistema sensorial é relevante para compreender como a criança significa o movimento de seu próprio corpo sob o efeito do movimento do cavalo "ao passo" e, ainda, como o ritmo repercute na aquisição de linguagem e no desenvolvimento infantil. Os pressupostos teóricos de Valerie Desjardins (2008) foram muito importantes para a reflexão sobre esses temas, porém esta teoria não será apresentada neste texto e pode ser encontrada na integra da tese.

${ }^{6}$ Por sistema sensorial, consideramos os processos de percepção, sensação e propriocepção de diferentes ordens (visuais, auditivas, gustativas, olfativas, táteis).
} 
Optamos por apresentar aqui o estudo de caso do sujeito HM e, ainda, questões sobre a relação construída entre a criança, o cavalo e a terapeuta durante o acompanhamento de outros três sujeitos, GN, RP e CR. A partir da análise dos dados de linguagem, buscamos explicitar a reinterpretação que fazemos, pautada na ND, dos pressupostos que a Equoterapia apresenta (ANDE-BRASIL, 2010, 2014). Com isso, pretende-se atualizar desse novo ponto de vista a presença do cavalo na cena equoterapêutica, o desenvolvimento da linguagem, bem como o papel do sistema sensorial nesse processo.

\section{EQUOTERAPIA: TEORIA E PRÁTICA}

Para a ANDE-BRASIL (2010, 2014), “[...] a linguagem é tomada enquanto um sistema de comunicação" (ANDE-BRASIL, 2014, p. 101). Sua proposta de trabalho fonoaudiológico com crianças portadoras de TEA se sustenta prioritariamente na formação do vínculo entre a criança e o cavalo, o que possibilitaria o desenvolvimento da linguagem (WILSON, TURNER, 1998; FREIRE, 1999; FREIRE, POTSCH, 2005; ESPINDULA, 2008; JESUS, 2009).

Assim, a Equoterapia:

[...] É um método terapêutico e educacional que utiliza o cavalo dentro de uma abordagem interdisciplinar nas áreas de saúde, educação e equitação buscando o desenvolvimento biopsicossocial de pessoas com deficiências e/ou com necessidades especiais (ANDE-BRASIL, 2010, p. 9).

O uso do cavalo em práticas terapêuticas é muito antigo e está associado historicamente à sensação de força e poder (devido ao porte físico e altura do animal), à sua mansidão, à fácil domesticação e à afetividade que demonstra aos homens e a outros animais. Mas o seu maior benefício está em seu movimento tridimensional que ocorre na andadura do passo. São movimentos sequenciados e simultâneos que transmitem ao praticante: movimentos no plano vertical - para cima e para baixo -; no plano horizontal - para direita e para a esquerda -; e nos eixos transversal e longitudinal - movimentos para frente e para trás (ANDEBRASIL, 2010, 2014).

Em relação à terapia fonoaudiológica de linguagem, a ANDE-BRASIL destaca como princípio fundamental que: "A exploração do cavalo como instrumento terapêutico garante, na terapia de linguagem, maior motivação, imprescindível para o sucesso da intervenção" (ANDE-BRASIL, 2014, p. 101). A linguagem, como já dissemos, é compreendida na literatura da área enquanto um sistema de comunicação e a concepçãode cérebro advém da Teoria Localizacionista ${ }^{7}$, ou seja, um órgão dividido em áreas cerebrais específicas e, dentre estas, as que são responsáveis pela aquisição de linguagem. Nesse sentido, o amadurecimento destas áreas propiciaria à criança a "capacidade" de perceber o meio, desde que seja um

${ }^{7} \mathrm{O}$ localizacionismo, como também é chamada tal teoria, argumenta que as funções da linguagem estão sediadas em regiões delimitadas do cérebro, independentes uma das outras, que poderiam ser especificadas a partir da correlação entre os sintomas e a localização de lesões (FREUD, 1891/1973). 
meio estimulante, o que, por consequência, desencadearia o desenvolvimento da linguagem (ESPINDULA, 2008; JESUS, 2009; ANDE-BRASIL, 2010).

Conta para esse propósito a ressalva de que se os "processos mentais se encontrarem imaturos, corre-se o risco de a terapia não ter êxito" (ANDEBRASIL, 2014, p. 101). Por este motivo, a ANDE-BRASIL recomenda que a terapia fonoaudiológica deva seguir os seguintes passos: iniciar o trabalho com a função de atenção básica e incluir outras funções, tais como:

[...] provas de atenção dentro do picadeiro. Posteriormente, inicia-se a habilitação da Percepção Visual, abrangendo áreas de Discriminação Visual, Reconhecimento, Orientação Espacial, Figura-Fundo, Coordenação Viso-Motora. Inicia-se a habilitação da Percepção Auditiva, com provas de Percepção e Discriminação Auditivas. Pode-se realizar provas de Percepção Visual em conjunto com provas de Percepção Auditiva: sons e suas respectivas figuras. Inicia-se a habilitação da Memória Visual e Memória Auditiva. Deve-se ter em mente que aprendizagem depende basicamente da motivação. Depois dessas etapas vencidas, a criança torna-se apta a receber e reter estímulos do meio e, naturalmente, inicia um processo de aprendizagem. É o momento propício para a intervenção interdisciplinar, onde se espera que a criança adquira Coordenação Motora Fina, Coordenação Motora Global, Esquema Corporal, Categorização, Orientação temporal, Raciocínio Lógico, funções mais elaboradas que propiciam a linguagem (ANDE-BRASIL, 2014, p. 102).

Contudo, não há uma formulação estruturada de protocolos ou de um conjunto de referências teóricas que sustentem o trabalho fonoaudiológico de avaliação e/ ou de terapia, tampouco o desenvolvimento das funções acima relacionadas. Como vemos a condução da ANDE-BRASIL e da literatura da área em relação ao acompanhamento fonoaudiológico de crianças portadoras de TEA/Autismo Infantil é sucinta e superficial.

\section{TRANSTORNO DO ESPECTRO AUTISTA (TEA): CONCEITOS TEÓRICOS}

Em 1867, o psiquiatra Henry Maudsley já incluía em seus estudos crianças com desordens mentais graves que apresentavam sintomas reconhecidos, posteriormente, na descrição da sintomatologia do autismo infantil.

Em 1943, Kanner descreveu sob o nome de "Distúrbios Autísticos do Contacto Afetivo" uma patologia cujas características eram: ausência de movimento antecipatório; não aconchego ao colo; linguagem alterada (repetição automática, descontextualidade no uso de palavras); ecolalia imediata e tardia; literalidade e inversão pronominal (JUNIOR, KUCZINSK, 2007). Kanner chamava a atenção, ainda, para o fato de as crianças terem melhor relação com objetos do que com pessoas, pois não mantinham contato através do olhar.

Nas décadas posteriores, o Autismo Infantil foi considerado uma patologia associada à psicose infantil e à esquizofrenia (DSM-I, 1952; DSM-II, 1968). Mais tarde, passou a ser visto como um quadro específico dentro da classificação de "Transtorno do Desenvolvimento Infantil" (DSM-III, 1980; CID-10, 1983; DSMIV, 1994). 
A constatação clínica de diferentes comportamentos de crianças portadoras de autismo e mesmo de diferentes tipos de autismo ${ }^{8}$ foi decisiva para a formulação do DSM-V, em 2013, quando a patologia passou a ser considerada como um espectro, com o objetivo de reunir suas múltiplas variações clínicas, recebendo, neste momento, a denominação de "Transtorno do Espectro Autista".

Os critérios decisivos para este diagnóstico são: 1) déficits clinicamente significativos e persistentes na comunicação social e nas interações sociais, manifestadas de diferentes maneiras: a. déficits expressivos na comunicação não verbal e verbal usadas para interação social, b. falta de reciprocidade social, c. incapacidade para desenvolver e manter relacionamentos de amizade apropriados para o estágio de desenvolvimento; 2) padrões restritos e repetitivos de comportamento, interesses e atividades, manifestados por, pelo menos, duas formas: a. comportamentos motores ou verbais estereotipados ou comportamentos sensoriais incomuns, b. excessiva adesão/aderência a rotinas e padrões ritualizados de comportamento, c. interesses restritos, fixos e intensos. Os sintomas devem estar presentes no início da infância e a linguagem é o ponto crucial para o diagnóstico.

Poucos estudos investigativos são realizados sobre os transtornos sensoriais da criança portadora de TEA, mesmo sabendo-se que frequentemente apresenta alguma alteração dessa ordem e que estes sistemas são intrínsecos às relações com o mundo externo (DAWSON, WATLING, 2000; DA COSTA, 2006; MARQUES, FERREIRA, ARRUDA, 2007; FERNANDES, 2008; CAMINHA, 2009; SCHMIDT, 2012; SOARES, BRAGA, 2014).

As crianças e adultos portadores de TEA apresentam respostas a estímulos sensoriais (sonoros, táteis, gustativos, olfativos, visuais) que podem ser peculiares, incluindo a hiper ou a hipossensibilidade. Desse modo, observamos, por exemplo, o comportamento de colocar as mãos nos ouvidos sugerindo sentir dor diante de um determinado som ou, ainda, de não reação à dor, caso se machuque seriamente.

Os relatos autobiográficos de adultos portadores de TEA, divulgados na última década, nos ajudam a compreender como interpretam o mundo, revelando e descrevendo os transtornos sensoriais auditivos, visuais, táteis, de imagem e esquema corporal que apresentam (SACKS, 1995; GRANDIN, SCARIANO, 1999; MUKHOPADHYAY, 2008; FLEISCHMANN, FLEISCHMANN, 2012; GRANDIN, PANEK, 2014).

\section{UMA REINTERPRETAÇÃO DA PRÁTICA FONOAUDIOLÓGICA NA EQUOTERAPIA A PARTIR DA NEUROLINGUÍSTICA DISCURSIVA (ND)}

Os pressupostos teóricos que norteiam a prática fonoaudiológica em Equoterapia, expostos anteriormente, tais como - (i) o conceito de linguagem

${ }^{8}$ Primário, observado no primeiro ano de vida; secundário, observado depois de um período de desenvolvimento normal; Síndrome de Asperger (com desenvolvimento mais sofisticado de linguagem e de sociabilização); comportamentos autísticos associados a diferentes patologias neurológicas ou genéticas (GILLBERG, 1990; JERUSALINSK, 1993; KUPFER, 2013). 
atrelado apenas ao desenvolvimento cerebral da criança; (ii) a desconsideração do papel da linguagem como mediação de conhecimento; (iii) a desvinculação entre o processo de aquisição de linguagem e o desenvolvimento do sistema sensorial como possibilidade de significação do mundo e (iv) a valorização da presença do cavalo como o mais importante vínculo terapêutico nos levaram a buscar outro referencial teórico, com a finalidade de explicar os efeitos dessa prática nas crianças portadoras de TEA.

A ND ${ }^{9}$ assume a linguagem como lugar de interação humana, socialmente determinada e historicamente construída, resultado de um trabalho coletivo; atividade constitutiva da subjetividade, da alteridade e de si própria como objeto de reflexão (FRANCHI, 1977). Associa-se a essa visão de linguagem um modelo dinâmico de funcionamento cerebral postulado pelo neuropsicólogo Luria (1981), baseado nos postulados de Vygotsky (1926/1979, 1934/1994), que recobre o desenvolvimento linguístico, cognitivo e social da criança (COUDRY; MORATO, 1990). Assim, nesta perspectiva, o cérebro é um órgão biológico e comum a todos os indivíduos da espécie, mas também se revela em sua singularidade, determinada pelas experiências do sujeito, no contexto histórico-cultural que o interpelam (COUDRY, 1988).

Navarro (2016) articula a teoria histórico-cultural desenvolvida por Vygotsky (1926/2004; 1934/1979) - e ampliada por Luria (1979/1991) -, a teoria de desenvolvimento motor e emocional da criança construída por Wallon (1934/1995, 1947/2008) e os estudos de Merleau-Ponty (1994) na área de Filosofia Fenomenológica, tendo como ponto de partida a ND, com o objetivo de propor uma compreensão do corpo por meio do sistema sensorial e da linguagem.

De acordo com Luria (1991), a linguagem é a condição que leva à formação da atividade consciente de estrutura complexa do homem, pois: reorganiza os processos de percepção do mundo exterior e cria novas leis a partir dessa percepção (classificação e generalização de objetos, formas, cores em grupos ou categorias); muda os processos de atenção (com a linguagem, o homem consegue dirigir arbitrariamente a sua atenção); reorganiza também os processos de memória e, por fim, constitui as complexas formas do pensamento (percepção, linguagem, atenção dirigida, memória, gestualidade e raciocínio intelectual).

9 "Diário de Narciso: Discurso e afasia" é a tese de Doutorado defendida por Maria Irma Hadler Coudry, em 1986, no Instituto de Estudos da Linguagem (IEL-Unicamp), orientada por Carlos Franchi e co-orientada por Haquira Osakabe, que inaugurou a área que reconhecemos atualmente como Neurolinguística Discursiva, desenvolvida no IEL/Unicamp. Nessa obra, Coudry analisa dados de linguagem de três sujeitos afásicos $(\mathrm{N}, \mathrm{P}, \mathrm{e} \mathrm{L})$ priorizando neles o exercício da subjetividade através da linguagem. A abordagem discursiva dirigida ao trabalho com a linguagem de sujeitos cérebro-lesados também possibilitou à autora realizar uma crítica reflexiva sobre as baterias de testes de avaliação dos sujeitos afásicos. A Neurolinguística tornou-se disciplina de graduação no IEL em 1983 e em 1987 uma área de concentração do programa de pós-graduação em Linguística. Em 1989, a partir da realização de um convênio entre Departamento de Linguística (DL/IEL) e o Departamento de Neurologia (DN/ FCM), nasceu o Centro de Convivência de Afásicos (CCA, dirigido para pessoas afásicas) e, em 2004 tiveram início as atividades do Centro de Convivência de Linguagens (CCazinho), dirigido a crianças e adolescentes portadores de diagnósticos na área de leitura e escrita. (COUDRY, 2002). 
Tais funções envolvem todo o cérebro em uma rede de estruturas e áreas, algumas específicas funcionando como base, outras menos especializadas e aptas a tecer relações dos mais diversos tipos que resultam em aprendizado, memória e práticas que podem ser adquiridas durante toda a vida (LURIA, 1991; COUDRY, FREIRE, 2005).

O referencial teórico de Henry Wallon se aproxima dos estudos lurianos por se ocupar também do desenvolvimento infantil do ponto de vista social e histórico, privilegiando o desenvolvimento motor infantil, os processos de sensação/ propriocepção/percepção e a aquisição de linguagem.

Wallon $(1995,2008)$ partilha com Vygotsky $(1979,1994)$ a ideia de que a atividade motora da criança começa de forma elementar, caracterizada por um conjunto de gestos sincréticos com significado filogenético. Inicialmente, esses gestos são a expressão de uma modulação tônica e emocional do ajuste da criança ao meio ambiente. Nesse momento, não há separação possível entre o indivíduo e o meio, sendo a motricidade a característica existencial e essencial da criança, respondendo às suas necessidades básicas e aos estados emocionais e relacionais.

Os movimentos da criança também dependem da qualidade e da quantidade de estímulo sensorial que a criança recebe na interação e na socialização com o mundo. É através de ações motoras que a criança explora o mundo sensorialmente, ao mesmo tempo em que descobre a si mesma, possibilitando que diferencie seu corpo do mundo exterior. A motricidade, de acordo com Wallon, vai desencadear representações e noções das coisas, constituindo-se como prelúdio da atividade simbólica, à medida que a realização dos gestos precede a palavra. Ou seja, a sensação/propriocepção/percepção são processos intrinsicamente relacionados à aquisição de linguagem.

Essas reflexões nos levam a reconhecer que existe um determinado funcionamento de linguagem por parte das crianças com diagnóstico de TEA, que passamos a compreender na relação com o desenvolvimento de seu sistema sensorial, perceptivo e vestibular que também parecem se sustentar com um funcionamento próprio. Assim, essas crianças, desde o nascimento, parecem explorar o mundo de uma maneira adversa, guiadas por uma organização interna distinta e que nem sempre pode ser compreendida pelo outro. Não é impossível imaginar que também experimentam o mundo de maneira distinta; mais distinta do que o esperado.

Tal como Wallon, Merleau-Ponty - nos estudos desenvolvidos na área da Filosofia Fenomenológica - também considera o movimento e a ação como bases para o desenvolvimento do ser humano e das funções cerebrais superiores, dando relevância nesse processo ao sistema sensorial. A consideração da teoria desenvolvida por Merleau-Ponty se deve ao fato de que, para o autor, as relações entre as percepções e as sensações são compreendidas como uma atitude corpórea em movimento, ideal para pensar a prática fonoaudiológica no contexto da Equoterapia em que os corpos (do praticante, do animal e do terapeuta) se mantêm em contínuo movimento guiado pela linguagem, acontecimento central e intrínseco aos procedimentos terapêuticos ali empregados. 
Merleau-Ponty (1945/1994), baseando-se nos estudos da Gestalt, compreende que a percepção, sob uma perspectiva neurofisiológica, não pode ser considerada como um acontecimento pontual e necessita de uma noção ampliada (campo) criadora de sentidos à medida que não existem sensações elementares e nem objetos isolados. Desse modo, a percepção passa a ser interpretada como algo não definitivo e não totalizado, mas provisória, sempre incompleta na relação com a sensação, com o corpo e com o movimento.

Seguindo com Merleau-Ponty, a concepção fenomenológica da percepção é entendida na experiência do corpo como campo criador de sentidos. Não se trata, portanto, de uma noção de percepção como uma representação mentalista, mas acontecimento da corporeidade e, como tal, uma expressão criadora a partir dos diferentes olhares sobre o mundo:

[...] O olhar obtém mais ou menos das coisas segundo a maneira pela qual ele as interroga, pela qual ele desliza ou se apoia nelas. Aprender a ver as cores é adquirir um certo estilo de visão, um novo uso do corpo próprio, é enriquecer e reorganizar o esquema corporal (MERLEAUPONTY, 1994, p. 212).

Para o autor, a percepção do corpo é confusa na imobilidade, pois lhe falta a intencionalidade do movimento que acompanha nosso acordo perceptivo com o mundo. Desse modo, as sensações aparecem associadas a movimentos e cada objeto convida à realização de um gesto, não havendo representação, mas criação e novas possibilidades de interpretação das diferentes situações existenciais.

Merleau-Ponty, Luria e Wallon, portanto, se aproximam teoricamente à medida que o movimento do corpo é a expressão da reorganização do sistema sensorial, linguístico e neurofuncional como um todo. Essa formulação teórica evidencia a questão do ritmo presente no movimento, nas diferentes percepções e na prática da Equoterapia, devido às características do passo do cavalo.

Assim, a partir deste aporte teórico constituído pela ND, a cena equoterapêutica como um todo ganha destaque e não apenas o cavalo. Sob esta perspectiva, analisa-se a importância do vínculo construído pela criança com o terapeuta e com o cavalo e, neste espaço, este último passa a ser delimitando como um ser de linguagem (com especificidades próprias). Isso porque, o terapeuta, ao se dirigir ao cavalo pela linguagem, possibilita que esta mesma linguagem possa vir a afetar a criança, caso ela se interesse pelo animal ou por algum aspecto dele.

Portanto, não se trata, de considerar o vínculo da criança com o cavalo como um acontecimento "natural", de transferência automática do animal para os seres humanos, mas sim como um acontecimento neurofuncional, psíquico e discursivo porque é mediado pela linguagem. Por outro lado, o processo neurofuncional envolvendo o sistema sensorial não se encerra em si mesmo, não está apartado do desenvolvimento da linguagem; ao contrário, faz a linguagem emergir, pois o cavalo e a criança se fundem em um só movimento e ritmo que propaga sensações no corpo/sujeito como um todo.

Diante dessa ressignificação discursivamente orientada da cena equoterapêutica, os princípios que regem a terapia fonoaudiológica na Equoterapia sob a regulamentação da ANDE BRASIL, como expostos anteriormente, 
não se sustentam à medida que a linguagem e o sistema sensorial, implicados nas significações veiculadas pela e na linguagem, ficam apartados naqueles princípios. Ou seja, a cena equoterapêutica pode implicar um processo em que a res(significação) de percepções e sensações primeiras que, nomeadas pelo outro na cultura e na língua, acaba por remeter aos aspectos psíquicos nelas envolvidos. Então, antes de um vínculo ser estabelecido como bom ou ruim, como prazeroso ou não, é preciso construir no corpo da criança o reconhecimento desses diferentes processos perceptuais.

É preciso explicitar que o cavalo demanda para o corpo da criança um conjunto de sensações que a equoterapeuta/fonoaudióloga significa como positivo, instaurando o cavalo como um outro que requer a possibilidade de laços contratuais entre ele e a criança. Esta afirmação pode ser compreendida à medida que pode haver, por parte da criança, uma demanda de linguagem e - como é o caso de crianças que, ao serem orientadas, mandam um beijo para o cavalo começar a andar - e, por parte do animal, uma resposta a partir dessa demanda.

Desse modo, na cena terapêutica, o cavalo atua como o outro da criança, aquele que responde à sua ação, ao mesmo tempo em que também a criança é afetada pela ação do cavalo, ou seja, pela ação desse outro. O cavalo torna-se um outro na linguagem quando passa pela linguagem da fonoaudióloga que, por sua vez, significa para a criança portadora de TEA esses acontecimentos de linguagem, instaurando entre eles os laços contratuais.

Destacando a questão de que a criança portadora de TEA tem dificuldade de interação, poderia se imaginar que colocá-la sobre o cavalo seria suficiente para que ela reconhecesse as propriocepções corporais como prazerosas e, então, estabelecer um vínculo com o cavalo? Algumas crianças não oferecem resistência para montar no cavalo; porém, demonstram repulsa em tocar o cavalo quando estão fora do corpo do animal ou, ainda, demonstram medo quando olham para o animal de lado, de baixo para cima ou de frente. Então, o vínculo em questão é com o cavalo em si ou com as sensações que demandam do seu corpo quando em movimento sobre o cavalo?

\section{ESTUDO DE CASO}

Para dar visibilidade à reinterpretação teórica que a ND possibilita ao acompanhamento fonoaudiológico, no contexto da Equoterapia, de crianças diagnosticadas como portadoras de TEA, apresentamos o estudo de caso ${ }^{10}$ do sujeito HM, e, em seguida, relatamos brevemente outros três casos, GN, RP e CR. Os aspectos privilegiados nas apresentações dessas cenas equoterápicas são os deslocamentos de posição do sujeito em relação ao vínculo com o cavalo e ao vínculo com a terapeuta, ao seu desenvolvimento de linguagem e, ainda, à posição da fonoaudióloga em relação ao animal e aos sujeitos.

${ }^{10}$ Esta pesquisa foi aprovada pelo Comitê de Ética em Pesquisas (SISNEP/CONEP) em 23/11/2011, sob o número 1076.0.146.000-11. 
A metodologia é de base heurística e permite descrever, analisar e compreender o funcionamento linguístico de sujeitos com dificuldades de linguagem (afásico ou portadores de outras patologias) como um processo (COUDRY, 1986/1988). Faz parte dessa metodologia o conceito de dado achado que dá relevância à singularidade do dado no contexto de sua ocorrência. Ou seja, por um lado a análise do dado ilumina os caminhos linguísticos tomados pelo sujeito ao longo do processo e, por outro, amplia e refina a própria teoria (COUDRY, 1996).

HM, sexo masculino, nasceu no dia 24/09/2010 e desenvolveu-se dentro dos parâmetros considerados normais do ponto de vista do desenvolvimento neuropsicomotor normal, exceto em relação à fala e à linguagem. Foi diagnosticado com TEA em março de 2013. O acompanhamento fonoaudiológico em Equoterapia iniciou-se em maio de 2013 (e se mantém), quando ele contava com dois anos e sete meses de idade.

No Centro de Equoterapia, nos primeiros contatos com HM, observou-se que ele não falava, não olhava para a terapeuta e apresentava-se muito agitado. Durante a montaria, não deixava tocar sua mão; seguia olhando para frente, sem parecer se interessar por nada específico. Se tentassem cantar, ele logo colocava as mãos no ouvido, como se estivesse incomodado. Ele também não encostava a mão no animal, gesto que levou aproximadamente um ano e meio para acontecer. Parecia não ter interesse por nenhuma pessoa, nem pelo cavalo.

Todos esses aspectos levam à consideração de que HM apresentava alterações em seu sistema sensorial. Como vimos, Luria postula que a linguagem tem uma relação intrínseca com os sistemas de percepção ou processos de percepção do mundo exterior e envolvem o funcionamento de todo o cérebro, em uma rede de estruturas e áreas, tecendo relações entre os mais diferentes aprendizados. Já para Luria e Merleau-Ponty (1999), o toque físico está relacionado ao sistema tátil e não se trata de uma sensação isolada à medida que, as sensações: “[...] podem influenciar-se mutuamente, sendo que o funcionamento de um órgão de sentido pode estimular ou reprimir o funcionamento de outro" (LURIA, 1991, p.15-16).

Durante a montaria, a propriocepção, o sistema vestibular e o tato de HM são continuamente estimulados e submetidos à relação com outras sensações. Isso acontece, devido ao efeito cinesioterápico promovido pelo passo do cavalo, independente da vontade do praticante. Assim, em um primeiro momento, pode-se dizer que o cavalo foi considerado como um agente cinesioterapêutico, promovendo sensações no corpo de HM, ajustando seu sistema sensorial.

Ao longo do acompanhamento, HM passou a nomear o cavalo e a mostrarse feliz quando percebia o caminho que a família fazia para ir ao Centro de Equoterapia, indícios de que ele não era indiferente às experiências que a Equoterapia the propiciava. Entretanto, nada disso garantia sua interação com o cavalo. Somente cerca de um ano depois do início da terapia é que HM passou a assumir o cavalo como um suposto "ser de linguagem", e isso se deu quando conseguiu interpretar que o fato de mandar um beijo para o animal fazia o animal andar. Nesse momento, o cavalo se tornou uma presença diferente para HM.

Também faz parte da Equoterapia mudanças de posição do praticante sobre o animal. HM resistia a essa mudança, mas quando experimentou o volteio 
terapêutico $^{11}$ passou a interagir mais com a terapeuta. Essa interação tinha características próprias: escassas, muito rápidas, marcadas por pouquíssimos olhares fugazes ou pelo sorriso. Trata-se, portanto, de uma determinada interação que era interpretada como crescente, pois ele passou a repetir a fala "Manda beijo pro Bob, HM". Ele repetia: "Beijo Bob" e, em seguida, fazia o gesto do beijo. Passou também a reproduzir enunciados dos desenhos animados que ele gostava de assistir.

Após dois anos e meio do início do acompanhamento, durante a montaria em posição de volteio, HM começou a repetir a fala de algum personagem de desenho animado que a terapeuta não reconhecia. Em um dado momento, ele disse "Manga", ao mesmo tempo em que fazia um movimento de pinça com os dedos das mãos, como se fosse colocar algo na boca para comer.

Tentando entrar na brincadeira, a terapeuta disse: "O que você vai comer, uma manga? Dá uma aqui!". Em seguida, pegou os dedos da mão de HM, fingindo que iria pegar a fruta de sua mão, colocando-a na boca e mastigando. HM rapidamente começou a rir e, olhou para a terapeuta, ao mesmo tempo em que repetia o mesmo gesto, como se estivesse comendo algo. Novamente, ela disse: "É uma manga? Dá aqui uma pra mim!", repetindo aqueles gestos. HM começou a gargalhar enquanto permanecia olhando para sua interlocutora. Esta brincadeira se prolongou por pelo menos dez minutos. Entretanto, cansada da brincadeira a terapeuta se recusou a continuá-la, mas HM, em cima do cavalo, pegava a mão da fonoaudióloga levando-a até a sua, insistindo para que brincasse com ele.

Esse dado é muito importante por diferentes razões: (i) HM, que já havia decorado as falas e gestos de um personagem de desenho animado, conseguiu se distanciar daquela cena e entrar em um jogo simbólico compartilhado com seu interlocutor; (ii) HM se mostrou capaz de colocar seu corpo em posição para a atividade, movido pela expectativa do que poderia vir a acontecer (VYGOTSKY, 2004); (iii) o cavalo, neste dado, perdeu a importância central que até então vinha mantendo, pois HM conferiu à terapeuta o papel de sua interlocutora, sem que isso dependesse da presença do cavalo. Entretanto, o cavalo continua sendo importante à medida que contém a agitação de HM, possibilitando-lhe focalizar a atenção. Todos estes acontecimentos interferem no funcionamento neurodinâmico cerebral de HM, assim como, possivelmente, rearranjam suas percepções e sua memória em função do vivido e de seus processos cognitivos (WALLON, 1995, 2008).

No percurso de HM, o cavalo exerceu diferentes papéis: inicialmente não havia demonstração de algum vínculo; depois passou a ser o vínculo exclusivo da criança, quando passou a responder aos comandos de HM, sendo investido de

11 O volteio terapêutico é uma adaptação dos exercícios propostos pelo volteio convencional. Este se define como uma atividade que envolve exercícios característicos da ginástica artística, dinâmicos, estáticos, além de acrobáticos combinados. No caso da Equoterapia, uma das possibilidades da realização do volteio terapêutico é realizar mudanças de posição sobre o cavalo. Neste caso, a criança fica com o corpo voltado ora para a lateral do cavalo, mantendo-se ora de frente para o profissional que o acompanha, ora de frente para a anca do animal. 
linguagem na cena terapêutica. Por outro lado, a fonoaudióloga também ocupou diferentes posições na cena equoterápica: deslocou-se de uma posição na qual não era considerada, para a de interlocutora de HM, quando este lhe atribuiu este papel.

Fenômeno similar em relação às diferentes posições assumidas pela criança, cavalo e terapeuta, ocorreu nos acompanhamentos equoterápicos de GN, RP e CR, os quais passamos a relatar brevemente, com foco neste aspecto.

GN foi diagnosticado com TEA aos 5 anos de idade e iniciou os atendimentos em Equoterapia em junho de 2013, aos 6a7m (e se mantém até o presente). Desde os primeiros encontros na Equoterapia, GN fazia perguntas repetidas sobre o que tem interesse ("Você tem cachorro? Ele é bravo? Ele cuida da casa?") independentemente de serem respondidas. Ele não respondia quando questionado; não mantinha o foco em algo específico; aparentemente prestava pouca atenção na sua interlocutora. A repetição de suas perguntas foi interpretada como uma busca pela interlocução. Entretanto, era possível observar sua dificuldade de se relacionar socialmente.

Ao longo do trabalho fonoaudiológico com GN, o cavalo desempenha diferentes papéis na cena equoterápica : i) atua como agente cinesioterapêutico, pois GN, quando montado no animal, segura com força a alça do cilhão e a rédea para guia-lo, diferente de quando está em solo, quando emprega pouquíssima força para segurar algum objeto; (ii) atua como agente postural, pois durante a montaria, a postura corporal de GN muda - sua cabeça permanece ereta, a cifose diminui significativamente, o quadril fica em posição correta (flexão, abdução e leve rotação), a linha de seu pé fica em posição adequada, ou seja, paralela ao cavalo, com o calcanhar ligeiramente mais baixo que a ponta do pé (mesmo quando seu pé está fora do estribo); (iii) atua como agente atencional, à medida que observa-se emGN melhor atenção quando montado do que quando está em solo, pois no primeiro caso, sabe que deve se manter atento aos comandos da terapeuta (meia-volta, círculo, alto ${ }^{12}$ ), lembrando-se de realizá-los corretamente.

Por último, o cavalo, no caso de GN, funciona como ponte para o jogo de linguagem. Como vimos, GN se mantinha fazendo repetidas perguntas sobre o animal. Entretanto, a vivência de GN nas sequências de acontecimentos em solo, como, por exemplo: pegar o cavalo no pasto, colocar seu cabresto, levar o animal para a baia, escovar e limpar o animal, colocar as mantas, contribuiu para que começasse a fazer perguntas diferentes sobre o cavalo.

GN, desde o início do acompanhamento, mantém um vínculo afetivo com o cavalo e, contrariando os pressupostos teóricos da Equoterapia, isso demonstra que o vínculo com o animal, por si só, não possibilita o desenvolvimento de linguagem, pois seus aspectos discursivos dependem da relação com o outro e com o mundo.

12 Em "meia-volta", o praticante descreve um semicírculo e depois obliquamente retorna à pista na mão oposta a que seguia anteriormente; "alto" é o comando de parar o cavalo em movimento; "círculo" determina que o praticante deve fazer um círculo e retomar a pista no ponto em que a havia deixado. 
No caso de RP, diagnosticado com TEA aos dois anos de idade, notamos que seus pais interagiam muito pouco com ele. $\mathrm{O}$ acompanhamento fonoaudiológico em Equoterapia teve início em abril de 2013, quando ele contava com 7a7m de idade, sendo finalizado em novembro de 2014, perfazendo um período de 19 meses.

Quando montado, sorria assim que o animal começava a andar, movimentando intensamente seu tronco para frente e para trás, passando incessantemente a mão no pescoço do cavalo, deitando-se vagarosamente sobre o animal e, por vezes, vocalizava, demonstrando muita satisfação. Não foi possível reconhecer no percurso de RP nenhuma demonstração de vínculo com o animal, mas parecia que ele buscava sentir o que o animal lhe transmitia sensorialmente enquanto estava montado. Ao observar RP sobre o cavalo, tinha-se a impressão de que ele procurava embalar e experimentar todo o seu corpo no movimento e no corpo do animal, formando com ele um par.

No caso de RP é relevante o fato de que, para além daquilo que o cavalo proporcionava a ele, através do movimento tridimensional incidindo no sensório e no motor como um todo e instigando o sistema sensorial, sua relação com o animal parecia de outra ordem. Os contínuos movimentos que RP fazia com o seu corpo enquanto estava sobre o cavalo, aparentemente, são uma resposta motora aos estímulos sensoriais que se originam no corpo do cavalo e passam pelo seu. Aparentemente, essa experiencia de sentir seu corpo e ser significado pela terapeuta merece relevância se consideramos que na sua historia de vida houve pouca interação entre ele e seus pais. Assim, a apatia de RP parece muito mais uma resposta a essa falta do que uma questão relativa ao diagnóstico que lhe foi atribuído.

$\mathrm{O}$ acompanhamento fonoaudiológico de CR na Equoterapia teve início em maio de 2013 e, devido ao retorno da família aos EUA, foi encerrado em janeiro de 2015, perfazendo um período de um ano e oito meses.

CR não criou vínculo com o animal que também não teve um papel de "ser de linguagem"; desde o início estabeleceu um vínculo importante com a terapeuta. Logo, no trabalho realizado, o cavalo se manteve como um instrumento, cuja presença parecia ser perfeitamente substituível por qualquer outro instrumento de atendimento fonoaudiológico em outro ambiente, como por exemplo, o brinquedo na clínica.

\section{CONSIDERAÇÕES FINAIS}

A reinterpretação possibilitada pela ND sobre o acompanhamento fonoaudiológico no contexto da Equoterapia expande e explica os acontecimentos da cena equoterapêutica como um todo, sem com isso perder de vista o sujeito, a fonoaudióloga e o cavalo como personagens estruturantes desse acontecimento. Isso se torna possível porque seu arcabouço teórico sustenta: (i) uma determinada noção de linguagem, de base discursiva, que privilegia afetiva, social e historicamente as propriocepções corporais da criança; (ii) a ampliação da reflexão 
sobre o papel do cavalo que, por vezes, pode ser o de um "ser de linguagem", o de uma "ponte" que possibilita a migração do vínculo do cavalo para a terapeuta ou, ainda, o de promover a "conformação corporal e psíquica" da criança, portadora ou não de TEA/Autismo Infantil. Assim, a ND se mostrou como um profícuo norteador teórico, metodológico e prático da atuação do fonoaudiólogo no contexto da Equoterapia, bem como de outros profissionais que atuam na área.

\section{REFERÊNCIAS}

ALVES, D. B. Reflexões sobre a prática da Equoterapia e o desenvolvimento de crianças com paralisia cerebral. 2014. 84f. Monografia (Departamento de Educação). Universidade Estadual do Rio de Janeiro (UERJ), Rio de Janeiro.

ALVES, D. B. Abordagem fonoaudiológica na equoterapia no atendimento de crianças com distúrbios de linguagem oral: estudo de casos clínicos. 2010, Dissertação (Mestrado em Fonoaudiologia) - Pontifícia Universidade Católica de São Paulo, São Paulo.

ANDRADE, G. P. S.; CUNHA, M. M. A importância da Equoterapia como instrumento de apoio no processo de ensino aprendizagem de crianças atendidas nesta modalidade terapêutica. Revista Eventos Pedagógicos v.5, n.2, p. 132 - 142, jun./jul. 2014.

ASSOCIAÇÃO AMERICANA DE PSIQUIATRIA, 1952. Diagnostic and Statistical Manual - Mental

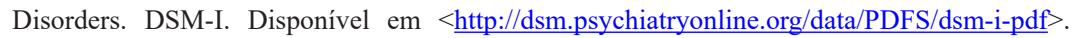
Acesso em 27/03/2018.

ASSOCIAÇÃO AMERICANA DE PSIQUIATRIA, 1987. Diagnostic and Statistical Manual of Mental Disorders. $3^{\text {a }}$ ed. rev. DSM-III-R. Disponível em $<$ http://dsm.psychiatryonline.org/data/PDFS/ dsm-iii-r.pdf>. Acesso em 27/03/2018.

ASSOCIAÇÃO AMERICANA DE PSIQUIATRIA. DSM-III: Manual Diagnóstico e Estatístico de Transtornos Mentais. São Paulo: Manole, 1980.

ASSOCIAÇÃO AMERICANA DE PSIQUIATRIA. DSM-IV: Manual Diagnóstico e Estatístico de Transtornos Mentais.4 ed. rev. Porto Alegre: Artmed, 1994.

ASSOCIAÇÃO AMERICANA DE PSIQUIATRIA. DSM-V: Manual Diagnóstico e Estatístico de Transtornos Mentais. 5 ed. rev. Porto Alegre: Artmed, 2014.

ANDE-BRASIL. Apostila do curso básico de Equoterapia da ANDE - BRASIL, 2010.

ANDE-BRASIL. Apostila do curso básico de Equoterapia da ANDE - BRASIL, 2014.

CAMINHA, R. C. Autismo: um transtorno de natureza sensorial? Psicologia Clínica, Rio de Janeiro, v.21, n.2, 2009.

CANTARELLI, M. R. D. V. Análise eletromiográfica do músculo orbicular da boca em crianças portadoras da síndrome da respiração bucal, pré e pós-tratamento em Equoterapia. 2006. 114f. Dissertação (Mestrado em Ciências Biológicas) - Universidade do Vale do Paraíba, São José dos Campos. 
COUDRY, M.I.H. Diário de Narciso. Discurso e afasia: análise discursiva de interlocuções com afásicos. Tese de doutorado. Unicamp, Campinas, 1986. Publicada em livro, São Paulo: Martins Fontes, 1988.

COUDRY, M.I.H. O que é dado em Neurolingüística? In: Maria Fausta Pereira Castro (Org.) O método e o dado no estudo da linguagem. Campinas: Editora da Unicamp, 1996.

COUDRY, M.I.H. Língua, discurso e a lógica da linguagem patológica. In: Cadernos da F. F. C./ Unesp., vol. 6, nº 2. Marília: Unesp, 1997.

COUDRY, M.I.H. Linguagem e Afasia: uma abordagem discursiva da Neurolinguística. In: Cadernos de Estudos Linguísticos, v. 42, pp. 99-129, 2002.

COUDRY, M.I.H. Caminhos da Neurolinguística Discursiva: o velho e o novo. In: COUDRY, M. I. H.; FREIRE, F. M. P.; ANDRADE, M. L. F.; SILVA, M. A. (Orgs). Caminhos da Neurolinguística Discursiva: teorização e práticas com a linguagem, 1 ed. Campinas: Mercado de Letras, 2010, pp. 279-399.

COUDRY, M.I.H; SCARPA, E. M. De como a avaliação de linguagem contribui para inaugurar ou sistematizar o déficit. In: Cadernos Distúrbios da Comunicação, Série Linguagem, v. 2. São Paulo: PUC, 1985.

COUDRY, M.I.H.; MORATO, E. M. Aspectos discursivos da afasia semântica. In: Cadernos de Estudos Lingüísticos, Campinas, n. 19, p. 127-146. 1990.

COUDRY, M.I.H.; FREIRE, F. M. P. O trabalho do cérebro e da linguagem: a vida e a sala de aula. Campinas: Cefiel/IEL/Unicamp. (Coleção Linguagem em foco), 2005.

COUDRY, M.I.H.; BORDIN, S. S. Afasia e Infância: registro do (in)esquecível. Cadernos de Estudos Linguísticos, v. 54 (1), pp.135-154, 2012.

DA COSTA, C. M. S. A importância do afeto através do toque no desenvolvimento cognitivo dos bebês. Monografia de pós-graduação Lato Sensu. Instituto Voz do Mestre. Universidade Cândido Mendes, 71 p. 2006

DAWSON, G.; WATLING, R. Interventions to facilitate auditory, visual, and motor integration in autism: A review of the evidence. Journal of Autism and Developmental Disorders, v. 30, n. 5, p. 415-421, 2000.

ESPINDULA, A. P. Efeitos da Equoterapia em praticantes autistas. 2008. 75f. Dissertação (Mestrado) - Patologia Geral, Universidade Federal do Triângulo Mineiro, 2008.

FERNANDES, F. S. O corpo no autismo. PSIC-Revista de Psicologia da Vetor Editora, Jan./Jun. v. 9, n. 1, p. 109-114, 2008.

FLEISCHMANN, A.; FLEISCHMANN, C. Carly's Voice: Breaking Through Autism. Touchstone: Nova Iorque, 2012.

FRANCHI, C. Linguagem, atividade constitutiva. Cadernos de Estudos Lingüísticos, n.22, p. 9-41, 1977. 
FREIRE, H.B.G. Equoterapia: teoria e técnica - uma experiência com crianças autista. São Paulo: Vetor, 1999.

FREIRE, H.B.G. Estudo de caso: Equoterapia com uma criança portadora de distúrbio autista atípico. 2003. Disponível em: < http://www.equoterapia.org.br/trabalhos/18091716.pdf > .

FREIRE, H.B.G. Pôneis como facilitadores na Equoterapia. Revista Equitar Therapies, 2015. Disponível em <http://www.equitar-br.com.br/poneis $>$

FREIRE, H. B. G.; POTSCH, R. R. O autista na Equoterapia: a descoberta do cavalo. 2005. Universidade Católica Dom Bosco, Campo Grande.

GILLBERG, C. Infantile autism: diagnosis and treatment. Acta Psychiatry Scand, 1990.

GRANDIN, T.; SCARIANO, M. M. Uma menina estranha: autobiografia de uma autista. São Paulo: Cia. das Letras, 1999.

GRANDIN, T., SCARIANO; M. M.; PANEK, R. El cérebro autista: el poder de uma mente autista. Barcelona: RBA Libros, 2014.

JESUS, E. P. O autista e os beneficios da Equoterapia. 2009. 39f. Monografia (Especialização em Educação Inclusiva), Universidade Candido Mendes, 2009.

KUPFER, M. C. Educação para o futuro. Psicanálise e Educação. São Paulo; Ed. Escuta: 2013.

LURIA, A. R. Curso de Psicologia Geral. Rio de Janeiro: Civilização Brasileira, 1991 [1979].(4 volumes).

LURIA, A. R. Fundamentos de neuropsicologia. São Paulo: Edusp, 1981.

MERLEAU-PONTY, M. Fenomenologia da percepção. São Paulo: Martins Fontes. 1994,672p. [1945]

MUKHOPADHYAY, T.R. How can I talk if my lips don't move? inside my autistic mind. New York, NY: Arcade Publishing. 2008

NAVARRO, P.R. Fonoaudiologia no contexto da equoterapia: um estudo neurolinguístico de criança com transtorno do espectro autista, Tese de doutorado (Linguística), Instituto de Estudos da Linguagem, UNICAMP, 145p. 2016

ROSAN, L.; BRACCIALli, L. M. P.; ARAUJO, R. C. T. Contribuição da Equoterapia para a Participação e Qualidade de Vida do Praticante com Paralisia Cerebral em Diferentes Contextos. Rev. Diálogos e Perspectivas em Educação Especial, v.3, n.1, p. 48-61, Jan.-Jun., 2016.

SCHMIDT, C. Temple Grandin e o autismo: uma análise do filme. Revista Brasileira de Educação Especial, Marília, v. 18, n. 2, p. 179-19, 2012.

SACKS, O. Um antropólogo em Marte. São Paulo: Companhia das Letras, 1995.

SILVA, C.H.; GRUBITS, S. Discussão sobre o efeito positivo da equoterapia em crianças cegas. Psic: Revista da Vetor Editora, São Paulo, v. 5, n. 2, p. 06-13, dez. 2004. 
SOARES, T., BRAGA, S.E.M. Relação da terapia de holding com a integração sensorial no autismo infantil. Revista Cientifica Interdisciplinar. Out./Dez. v.1, n.2, 2014.

STARKE, A.C.; ALBIERO, J.F.G. Equoterapia no cotidiano dos praticantes: Os reflexos do Projeto de Equoterapia da Universidade Regional de Blumenau (PROEQUO - FURB). Cataventos Revista de Extensão da Universidade de Cruz Alta, v.2, n.1. 2010

VALLE, L. M. O.; NISHIMORI, A. Y. NEMR, K. Atuação fonoaudiológica na Equoterapia. Revista CEFAC, vol 16, n. 2, p. 511-523, 2014.

VYGOTSKY, L. S. Teoria e método em psicologia. 2.ed. São Paulo: Martins Fontes, 1926/1994.

VYGOTSKY, L. S. Pensamento e linguagem. Lisboa: Antídoto, 1979 [1934].

VYGOTSKY, L. S. A formação social da mente. São Paulo: Martins Fontes, 1994.

VYGOTSKY, L. S. A psicologia e a pedagogia da atenção. In: Psicologia Pedagógica. São Paulo:Martins Fontes, 2004 [1926]

WALLON, H. As origens do caráter. São Paulo: Nova Alexandria, 1934/1995.

WALlON, H. Princípios da Psicologia Aplicada. São Paulo: Companhia Nacional, 1930/19.

WALLON, H. Do ato ao pensamento: ensaio de psicologia comparada. São Paulo: Vozes, 2008. 